dấu phẩy gặp ở cả 2 nhóm Microsporum và Trichophyton thuộc cả 2 nhóm nhiễm nấm nội sợi và ngoại sợi, đặc biệt trong nghiên cứu của chúng tôi ghi nhận nhiều trường hợp nhiễm T.verrucosum có những dấu hiệu này. T.verrucosum gây bệnh theo cả cơ chế nhiễm nấm nội-ngoại sợi, và hình ảnh ghi nhận trên dermoscopy thường có đủ tất cả các dấu hiệu nhiễm nấm da đầu hay gặp bao gồm tóc hình dấu phẩy, tóc hình xoắn nút chai, hình mã vạch, hình zic-zắc, tóc gãy và chấm đen [6].

\section{KẾT LUẬN}

Dermoscopy có giá trị cao trong chẩn đoán nấm da đầu với độ nhạy $95,1 \%$, độ đặc hiệu $33,3 \%$, giá trị dự báo dương tính $83 \%$, giá trị dự báo âm tính $66,7 \%$. Các dấu hiệu hay gặp trên dermoscopy bao gồm: tóc gãy, tóc hình khối, vảy da quanh chân tóc, tóc hình zic-zắc, tóc hình dấu phẩy, hình mã vạch, vỏ bọc trắng gần da đàu, vảy da lan toả, chấm đen. Trong đó, dấu hiệu vỏ bọc trắng gần da đầu có giá trị phân biệt giữa nhiễm chủng nấm Trichophyton và Microsporum.
TÀI LIỆU THAM KHẢO

1. Hay R.J. (2017). Tinea Capitis: Current Status. Mycopathologia, 182(1-2), 87-93.

2. Waśkiel-Burnat $A_{\text {., }}$ Rakowska $A_{\text {., }}$ Sikora M. et al (2020).Trichoscopy of Tinea Capitis: A Systematic Review. Dermatol Ther (Heidelb), 10(1), 43-52.

3. Dhaille F., Dillies A.S., Dessirier F. et al (2019). A single typical trichoscopic feature is predictive of tinea capitis: a prospective multicentre study. British Journal of Dermatology, 181(5), 1046-1051.

4. Isa R.I., Amaya B.Y., Pimentel M.I. et al (2014). Dermoscopy in tinea capitis: a prospective study on 43 patients. Medicina Cutanea Ibero-Latino-Americana, 42(1-3), 18-22.

5. Genedy R.M., Sorour O.A., Elokazy M.A. (2021). Trichoscopic signs of tinea capitis: a guide for selection of appropriate antifungal. International Journal of Dermatology, 60(4), 471-481.

6. Bourezane Y.(2017). Analysis of trichoscopic signs observed in 24 patients presenting tinea capitis: hypotheses based on physiopathology and proposed new classification, Elsevier.

7. Ekiz O., Şen B., Rifaioğlu E. et al (2014). Trichoscopy in paediatric patients with tinea capitis: a useful method to differentiate from alopecia areata. Journal of the European Academy of Dermatology and Venereology, 28(9), 1255-1258.

\title{
ĐÁNH GIÁ HIÊ̂U QUẢ GIẢM ĐAU ĐƯỜNG NGOÀI MÀNG CỨNG NGỰC BẰNG ROPIVACAIN KẾT HỢP FENTANYL DO BÊ̂NH NHÂN TỰ ĐIỀU KHIỂN SAU MỔ MỞ VÙNG BƯNG
}

\section{Trần Hoài Nam*, Nguyễn Minh Lý**, Hoàng Văn Chương*}

\section{TÓM TĂT}

Muc tiêu: Đánh giá hiệu quả giảm đau sau mổ mở vǔng bụng của gây tể ngoài màng cứng ngực bằng ropivacain kêt hợp fentanyl theo phương thức bệnh nhân tự điều khiển. Phướng pháp nghiên cứu: Can nghiệm lâm sàng ngẫu nhiên có so sánh, nghiên cứu trêñ 105 bệnh nhân ASA $1-3$, tuổi $\geq 18$, có chỉ định phẫu thuât mở ổ bụng, được giảm đau sau mổ bằng gây tê ngoài màng cứng ngực theo phương thức bệnh nhân tự điều khiển. Bệnh nhân được chia thành 3 nhóm, mỗi nhóm gồm 35 bệnh nhân. Hỗn hợp thuốc sử dụng giảm đau sau mổ là fentanyl $2 \mathrm{mcg} / \mathrm{ml}$ và lần lượt với ropivacain $0,1 \%$ ở nhóm I, ropivacain $0,125 \%$ ở nhóm II và ropivacain $0,2 \%$ ớ nhóm III. Đánh giá mức độ giảm đau dựa vào thang điểm VAS theo các thời điểm trong 72 giờ sau phẫu thuật. Kết quả: Điểm VAS hạ xuống dưới 4 khi nghỉ

*Học viện Quân y

**Bêenh viện Trung ương Quân đôi 108

Chịu trách nhiệm chính: Trân Hoài Nam

Email: namb5v103@gmail.com

Ngày nhận bài: 4.3.2021

Ngày phản biên khoa hoc: 22.4.2021

Ngày duyệt bài: 4.5.2021 sau 15 phút và khi vận động là sau 16 giờ sau mổ. Điểm VAS trung bình nhóm II tương đương nhóm III $(p>0,05)$ và thấp hơn nhóm I ở cả lúc nghỉ và lúc vận động $(p<0,05)$. Tỷ lệ hài lòng và rất hài lòng của bệnh nhân ở nhóm II là $100 \%$, cao hơn đáng kể so với nhóm I $(82,9 \%)$ và nhóm III $(77,1 \%)(p<0,001)$. Kết luận: Giảm đau ngoài NMC do người bệnh tự điệu khiển bằng ropivacain và fentanyl ở người bênh phẫu thuật mở ổ bụng mang lại hiệu quả giảm đau đáng kể. Trong đó, hỗn hợp ropivacaine $0,125 \%$ và fentanyl cho hiệu quả giảm đau tốt nhất.

Tư khóa: ropivacain,PCEA, giảm đau ngoài màng cứng, phẫu thuật ổ bụng mở

\section{SUMMARY}

\section{AN EVALUATION OF EFFICACY OF PATIENT-CONTROLLED THORACIC EPIDURAL ANALGESIA USING THE COMBINATION OF ROPIVACAINE AND FENTANYL FOR PATIENTS UNDERGOING OPEN ABDOMINAL SURGERY}

Objectives: To evaluate the efficacy of postoperative patient-controlled epidural analgesia using the combination of ropivacain and fentanyl for open abdominal surgery. Methods: A randomized 
comparative clinical trial was performed on 3 groups of patients, each of which contained 35 cases with indication for open abdominal surgery. The medications applied for postoperative analgesia was made up of fentanyl $2 \mathrm{mcg} / \mathrm{ml}$ combined with ropivacaine $0.1 \%$ in group $I$, ropivacaine $0.125 \%$ in group II and ropivacaine $0.2 \%$ in group III. The effectiveness of postoperative analgesia based on VAS score was documented at various investigated time points within 72 hours after surgery. Results: The VAS score at rest decreased to less than 3 after 15 minutes and at motion after 16 hours. The average of VAS score in the group II at rest and at motion was similar with the group III $(p>0.05)$ and significantly lower than those in its two counterparts $(p<0.05)$. The percentage of patients experiencing satisfaction and very satisfaction in the group II, I and III were $100 \%, 82.9 \%$ and $77.1 \%$, respectively $(p<0.001)$. Conclusion: Postoperative patient-controlled epidural analgesia using the combination of fentanyl and various concentrations of ropivacaine provided significantly analgesic efficacy to patients undergoing open abdominal surgery. Among the concentrations, ropivacaine $0,125 \%$ was the most efficient for postoperative analgesia when combined with fentanyl.

Tư khóa: ropivacaine, fentanyl, thoracic epidural anesthesia, open-abdominal surgery

\section{I. ĐĂT VẤN ĐỀ}

Gây tê ngoài màng cứng (NMC) ngực là phương pháp giảm đau sau mổ hiệu quả, thường được áp dụng cho các phẫu thuật lớn, gây đau nhiều ở vùng ngực và bụng, đặc biệt là mổ mở ổ bụng. Phương thức bệnh nhân tự điều khiển (PCA) đã được chứng minh sự ưu việt về hiệu quả giảm đau, tính an toàn và tiết kiệm thuốc so với các phương thức truyền thuốc khác. Nhiều loại thuốc tê đã được áp dụng để giảm đau sau mổ bằng đường ngoài màng cứng [3] [5]. Ropivacain là một loại thuốc gây tê thế hệ với đăc điểm là thời gian tác dung kéo dài, ít ức chế vận động, độc tính thấp với hệ thần kinh và tim mạch [7] nên hiện nay được sử dụng rộng rãi trong vô cảm cho phẫu thuật cũng như giảm đau sau mổ. Tại Việt Nam, đã có một số nghiên cứu về sử dụng ropivacain trong gây tê ngoài màng cứng để giảm đau sau mổ ở các phẫu thuật như phẫu thuật thay khớp háng, phẫu thuật ngực... Tuy nhiên chưa có nghiên cứu đánh giá hiệu quả giảm đau sau mổ mở ổ bụng của gây tê ngoài màng cứng ngực theo phương thức bệnh nhân tự điều khiển bằng ropivacain ở các nồng độ khác nhau. Nên chúng tôi thực hiên đề tài này nhằm so sánh hiệu quả giảm đau và tìm ra nồng độ ropivacain tối ưu.

\section{II. ĐỐI TƯỢNG VÀ PHƯƠNG PHÁP NGHIÊN CỨU}

2.1. Đối tượng: 105 bênh nhân tuổi $\geq 18$, ASA 1-3, có chỉ định phẫu thuật mở ổ bụng tại
Bệnh viện Quân y 103 trong thời gian từ tháng 04 năm 2015 đến tháng 07 năm 2017.

Tiêu chuẩn lưa chọn: Các bệnh nhân được giảm đau sau mố bằng gây tê ngoài màng cứng ngực theo phương thức bênh nhân tự điều khiển với hỗn hợp thuốc ropivacain kết hợp fentanyl.

Tiêu chuẩn loại trừ: Loại trừ những bệnh nhân có biến chứng về phẫu thuật, biến chứng về gây mê hoặc không thu thập đủ số liệu.

2.2. Phướng pháp. Nghiên cứu thử nghiệm lâm sàng có so sánh trên 105 bệnh nhân, sử dụng hỗn hợp ropivacain ở 3 nồng độ khác nhau kết hợp fentanyl $2 \mathrm{mcg} / \mathrm{ml}$, chia thành 3 nhóm: nhóm I $(\mathrm{n}=35)$ dùng ropivacain $0,1 \%$; nhóm 2 $(\mathrm{n}=35)$ dùng ropivacain $0,125 \%$; nhóm $3(\mathrm{n}=$ 35 ) dùng ropivacain $0,2 \%$.

Phương pháp tiến hành. Bệnh nhân được chuẩn bị mổ thường quy, được giải thích kỹ, đồng ý thực hiện kỹ thuật và được hướng dần cách sử dụng thước VAS.

Tại phòng mổ: Bệnh nhân được theo dõi bằng monitor, thở oxy, đặt đường truyền ngoại vi. Đặt catheter NMC ngực ở tư thế nằm nghiêng dưới gây tê tại chỗ. Test vị trí catheter bằng $3 \mathrm{ml}$ lidocain 1,5\% kết hợp adrenalin 1/200.000.

Gây mê NKQ theo quy trình chung: Khởi mê bằng tiêm tĩnh mạch propofol $1,5-2 \mathrm{mg} / \mathrm{kg}$, fentanyl $2 \mathrm{mcg} / \mathrm{kg}$, rocuronium $0,6 \mathrm{mg} / \mathrm{kg}$. Duy trì mê bằng servofluran $(2-3 \%)$, thuốc giãn cơ rocuronium, giảm đau trong mổ bằng fentanyl ngắt quãng (không sử dụng giảm đau đường ngoài màng cứng). Ngừng thuốc mê khi bắt đầu khâu đóng da. Kết thúc phẫu thuật, bệnh nhân được rút ống NKQ khi đủ tiêu chuẩn.

Tiến hành giảm đau sau mổ khi mạch, huyết áp, SpO2 ổn định và điểm VAS $\geq 4$. Nếu VAS $<4$ thì theo dõi và đánh giá lại sau mỗi 15 phút. Cài đặt máy PCEA: Liều đầu (initial dose) tính theo cồng thức sau: thể tích $(\mathrm{ml})=$ [chiêu cao $(\mathrm{cm})-$ 100]/10; liêu bolus $3 \mathrm{ml}$, thời gian khóa 10 phút, liều duy trì $3 \mathrm{ml} / \mathrm{giờ}$, tổng liều giới han trong 12 giờ là $30 \mathrm{ml}$. Nếu điểm VAS $\geq 4$ sau 3 lần bấm PCEA thì tiêm tĩnh mạch chậm ketogesic $30 \mathrm{mg}$, nhắc lại sau 4 giờ, liều tối đa trong 24 giờ là $90 \mathrm{mg}$.

Các chỉ tiêu đánh giá bao gồm: đặc điểm chung như tuổi, giới tính, chiều cao, cân nặng, BMI; thời gian khởi phát giảm đau, số phân đốt da bị ức chế cảm giác đau, đánh giá mức độ giảm đau dựa vào thang điểm đau VAS lúc nghì và lúc ho/vận động theo các thời điểm sau phẩu thuật; tổng lượng thuốc giảm đau đã dùng sau mổ; số lần bẩm PCEA và tỉ lệ $A / D$; số lần sử dung liều giải cứu đau; mức độ hài lòng của bệnh nhân theo các mức: rất không hài lòng - 
không hài lòng-bình thường-hài lòng-rất hài lòng.

Các chỉ tiêu được ghi lại tại các thời điểm sau: $\mathrm{H}_{0}$ (trước tiêm thuốc); $\mathrm{H}_{0,25}$ (sau tiêm 15 phút); $H_{0,5}$ (sau tiêm 30 phút); $H_{1}$ (sau tiêm 1 giờ); $\mathrm{H}_{2}$ (sau tiêm 2 giờ); ); $\mathrm{H}_{4}$ (sau tiêm 4 III. KẾT QUẢ NGHIÊN CứU

\section{1. Đắc điểm chung}

\section{Bảng 1. Đặc điểm chung bệnh nhân}

\begin{tabular}{|c|c|c|c|c|c|}
\hline \multicolumn{2}{|c|}{ Phân bố Nhóm } & $\begin{array}{l}\text { Nhóm I } \\
(n=35)\end{array}$ & $\begin{array}{c}\text { Nhóm II } \\
(n=35)\end{array}$ & $\begin{array}{c}\text { Nhóm III } \\
(n=35)\end{array}$ & $\mathbf{p}$ \\
\hline \multirow{2}{*}{ Giới tính (\%) } & Nam & 54,3 & 48,6 & 68,6 & \multirow{2}{*}{$>0,05$} \\
\hline & Nữ & 45,7 & 51,4 & 31,4 & \\
\hline \multirow{2}{*}{ Tuổi (năm) } & $\bar{x} \pm S D$ & $56,7 \pm 13,4$ & $62,2 \pm 9,8$ & $58,2 \pm 12,6$ & \multirow[b]{2}{*}{$>0,05$} \\
\hline & Min - Max & $24-88$ & $50-85$ & $28-81$ & \\
\hline \multirow{2}{*}{$\begin{array}{l}\text { Chiêu cao } \\
\text { (cm) }\end{array}$} & $\bar{x} \pm S D$ & $156,6 \pm 7,8$ & $158,2 \pm 7,8$ & $155,5 \pm 8,2$ & \multirow{2}{*}{$>0,05$} \\
\hline & Min - Max & $143-171$ & $145-171$ & $144-170$ & \\
\hline \multirow{2}{*}{$\begin{array}{c}\text { Cân nắng } \\
(\mathrm{kg})\end{array}$} & $\bar{x} \pm \mathrm{SD}$ & $48,7 \pm 8,1$ & $49,6 \pm 7,3$ & $50,3 \pm 10,2$ & \multirow{2}{*}{$>0,05$} \\
\hline & Min - Max & $35-68,5$ & $36,2-65,6$ & $37,8-79,1$ & \\
\hline \multirow{2}{*}{$\begin{array}{c}\mathrm{BMI} \\
\left(\mathrm{kg} / \mathrm{m}^{2}\right)\end{array}$} & $\bar{x} \pm \mathrm{SD}$ & $19,8 \pm 2,5$ & $19,8 \pm 2,3$ & $20,8 \pm 3,7$ & \multirow{2}{*}{$>0,05$} \\
\hline & Min - Max & $14,2-23,7$ & $13,8-24,3$ & $16,2-32,5$ & \\
\hline
\end{tabular}

Kết quả nghiên cứu cho thấy sự khác biệt về tuổi, cân nặng, chiều cao, BMI giữa các nhóm nghiên cứu không có ý nghĩa thống kê với p > 0,05.

\section{Bảng 2. Phân loại phẫu thuật}

\begin{tabular}{|c|c|c|c|c|c|}
\hline Loại phẫu thuật & $\begin{array}{c}\text { Nhóm I } \\
\mathbf{n}(\mathbf{\%})\end{array}$ & $\begin{array}{c}\text { Nhóm II } \\
\mathbf{n}(\mathbf{\%})\end{array}$ & $\begin{array}{c}\text { Nhóm III } \\
\mathbf{n}(\mathbf{\%})\end{array}$ & Tổng & p \\
\hline Cắt đoạn dạ dày & $16(45,6 \%)$ & $19(54,1 \%)$ & $20(57,1 \%)$ & $55(52,4 \%)$ & \\
\hline Cắt đoạn đại tràng & $5(14,3 \%)$ & $5(14,3 \%)$ & $1(2,9 \%)$ & $11(10,4 \%)$ & $>$ \\
\hline Cắt toàn bộ dạ dày & $7(20 \%)$ & $3(8,6 \%)$ & $4(11,4 \%)$ & $14(13,3 \%)$ & 0,05 \\
\hline Cắt toàn bộ đại tràng & $0(0 \%)$ & $1(2,9 \%)$ & $0(0 \%)$ & $1(1 \%)$ & \\
\hline Khác & $6(17,1 \%)$ & $7(20 \%)$ & $11(31,1 \%)$ & $24(22,8)$ & \\
\hline Tống & $\mathbf{3 5 ( 1 0 0 \% )}$ & $\mathbf{3 5 ( 1 0 0 \% )}$ & $\mathbf{3 5 ( 1 0 0 \% )}$ & $\mathbf{1 0 5 ( 1 0 0 \%}$ & \\
\hline
\end{tabular}

Phần lớn bênh cần phẫu thuât của đối tượng là cắt đoan da dày (trên $50 \%$ ). Sư phân bố về phân loại phẫu thuật giữa 3 nhóm là tương đương nhau $(p>0,05)$.

\subsection{Hiêu quả giảm đau}

\section{Bảng 3. Liều lượng thuốc sử dụng cho bệnh nhân}

\begin{tabular}{|c|c|c|c|c|c|}
\hline Nhór & & $\begin{array}{l}\text { Nhóm I } \\
(n=35)\end{array}$ & $\begin{array}{c}\text { Nhóm II } \\
(n=35)\end{array}$ & $\begin{array}{c}\text { Nhóm III } \\
(n=35)\end{array}$ & $\mathbf{p}$ \\
\hline Thể tích bolus đâu & $\bar{x} \pm \mathrm{SD}$ & $5,66 \pm 0,78$ & $5,82 \pm 0,78$ & $5,55 \pm 0,82$ & \\
\hline tiên (ml) & Min - Max & $4,3-7,1$ & $4,5-7,1$ & $4,4-7$ & $>0,05$ \\
\hline Tổng liều & ${ }^{x} \pm \mathrm{SD}$ & $232,9 \pm 5,8$ & $276,2 \pm 17,0$ & $446,1 \pm 6,0$ & \\
\hline Ropivacain (mg) & Min - Max & $222-244$ & $221-297,5$ & $442-472$ & $<0,0$ \\
\hline Tổng liêu fentanyl & $\bar{x} \pm \mathrm{SD}$ & $451,3 \pm 12,8$ & $445,4 \pm 20,1$ & $446,1 \pm 6,0$ & \\
\hline$(\mu g)$ & Min - Max & $401-472$ & $334-462$ & $442-472$ & 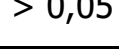 \\
\hline Số phân đốt bị ức & $\bar{x} \pm S D$ & $6,37 \pm 0,84$ & $6,48 \pm 1,27$ & $6,63 \pm 1,14$ & 5 \\
\hline chế & Min - Max & $5-8$ & $5-8$ & $5-8$ & כ \\
\hline Thời gian khởi phát & $x \pm S D$ & $8,86 \pm 1,68$ & $8,89 \pm 1,97$ & $8,83 \pm 1,98$ & \\
\hline giảm đau (phút) & Min - Max & $7-14$ & $7-14$ & $7-14$ & \\
\hline
\end{tabular}

Thế tích bolus đâu tiên và tống liều fentanyl không có sự khác biệt giữa các nhóm ( $p>0,05)$. Tống liều ropivacain trung bình tăng dần lân lượt ở các nhóm I, II và III ( $p<0,001)$, trong đó nhóm III là nhóm có tổng liều ropivacain cao nhất là 446,1 $\pm 6,0 \mathrm{ml}$.

Bảng 4. Số lân yêu cầu (demand) và số lân yêu câu thành công (actual)

\begin{tabular}{|c|c|c|c|c|}
\hline Đặc điểm & $\begin{array}{c}\text { Nhóm } \mathbf{I} \\
(\mathbf{n = 3 5}) \overline{\mathbf{X}} \pm \mathbf{S D}\end{array}$ & $\begin{array}{c}\text { Nhóm II } \\
(\mathbf{n = 3 5}) \overline{\mathbf{X}} \pm \mathbf{S D}\end{array}$ & $\begin{array}{c}\text { Nhóm III } \\
(\mathbf{n = 3 5}) \overline{\mathbf{X}} \pm \mathbf{S D}\end{array}$ & $\mathbf{p}$ \\
\hline Số lần bấm & $18,2 \pm 0,8$ & $15,9 \pm 0,8$ & $15,7 \pm 0,8$ & $<0,001$ \\
\hline
\end{tabular}




\begin{tabular}{|c|c|c|c|c|}
\hline Số lần bấm thành công & $16,1 \pm 0,9$ & $13,8 \pm 0,9$ & $12,3 \pm 0,7$ & $<0,001$ \\
\hline Tỷ lệ (A/D) (\%) & $88,4 \pm 2,3$ & $87,2 \pm 7,8$ & $78,2 \pm 5,9$ & $<0,001$ \\
\hline
\end{tabular}

Số lần bấm của nhóm II thấp hơn hằn nhóm I và nhóm III (15,9 lần so với 18,2 lần và 18,7 lần). Và sự khác biệt biệt có ý nghĩa thống kê với $p<0,001$. Tổng số lần bấm của đối tượng ở nhóm II và nhóm III thấp hơn so với nhóm I và sự khác biệt này cũng có ý nghĩa thống kê với p<0,001.

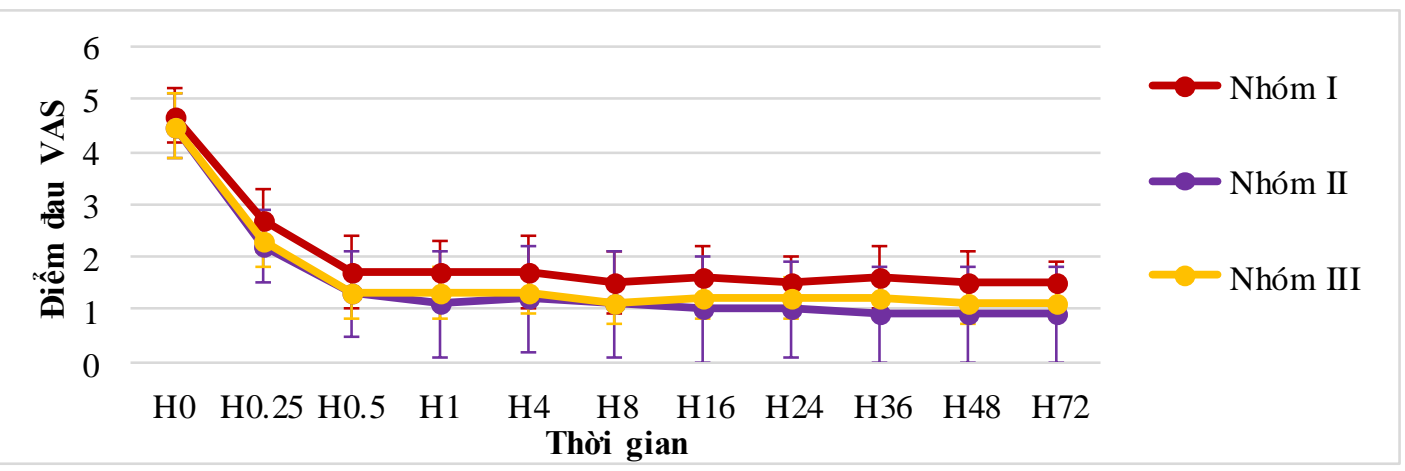

\section{Biểu đồ 1. Điểm VAS trung bình lúc nghỉ ở các thời điểm}

Điểm VAS khi nghỉ hạ xuống dưới 3 kể từ thời điểm 15 phút sau mổ. Trong đó, điểm đau VAS lúc nghỉ của nhóm II thấp hơn hẳn so với nhóm I (sự khác biệt giữa nhóm có ý nghĩa thống kê với $p<0,05)$, và tương đương với nhóm III.

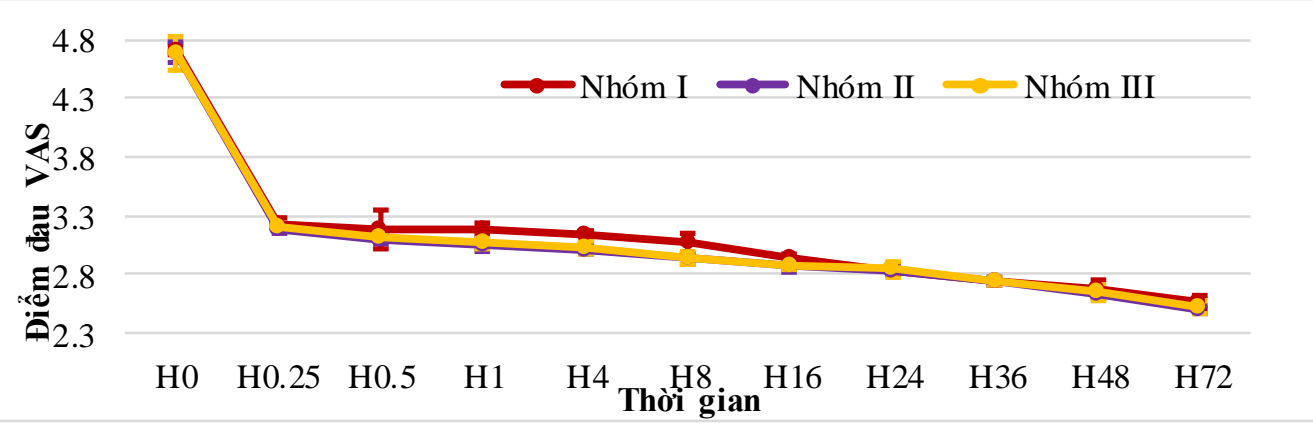

Biểu đồ 2. Điểm VAS khi ho/vận động ở các thời điểm

Điểm VAS khi ho/vận động hạ xuống dưới 3 kể từ thời điểm 16h sau mổ. Tương tự với đểm VAS lúc nghỉ, điểm VAS khi vận động của nhóm II tương đương với nhóm III và thấp hớn so với nhóm I, sự khác biệt có ý nghĩa thống kê với $p<0,05$.

\section{Mức độ hài lòng}

\section{Bảng 5. Phân bố tỉ lệ mức độ hài lòng của bệnh nhân}

\begin{tabular}{|c|c|c|c|c|c|c|c|}
\hline \multirow{2}{*}{ Mức độ Nhóm } & \multicolumn{2}{|c|}{ Nhóm I } & \multicolumn{2}{|c|}{ Nhóm II } & \multicolumn{2}{|c|}{ Nhóm III } & \multirow{5}{*}{$p<0,001$} \\
\hline & $\mathbf{n}$ & $\%$ & $\mathbf{n}$ & $\%$ & $\mathbf{n}$ & $\%$ & \\
\hline Bình thường & 6 & 17,1 & 0 & 0 & 8 & 22,9 & \\
\hline Hài lòng & 17 & 48,6 & 16 & 45,7 & 23 & 65,7 & \\
\hline Rất hài lòng & 12 & 34,3 & 19 & 54,3 & 4 & 11,4 & \\
\hline Tống & 35 & 100 & 35 & 100 & 35 & 100 & \\
\hline
\end{tabular}

Trong 3 nhóm chỉ có nhóm II có $100 \%$ đối tượng cảm thây hài lòng trở lên). Nhóm I có 17 đối tượng $(48,6 \%)$ cảm thây hài lòng và 12 đối tượng $(34,3 \%)$ cảm thấy rất hài lòng và còn lại là thấy bình thường $(17,1 \%)$. Nhóm III có 23 đối tượng $(65,7 \%)$ cảm thấy hài lòng và 4 đối tượng $(11,4 \%)$ cảm thấy rất hài lòng và còn lại là thấy bình thường (22,9\%). Sự khác biệt giữa 3 nhóm có ý nghĩa thống kê $(p<0,001)$.

\section{BÀN LUÂ̂N}

Các kết quả về thông tin chung giữa các nhóm nghiên cứu cho thây sự đồng nhất về đặc điểm các bệnh nhân tham gia, giúp nghiên cứu loại bỏ các yễu tố gây nhiễu ảnh hưởng tới kết quả đạt được.

Tổng liều Ropivacain trung bình tăng dần lần lượt ở trong nhóm I, II và III, trong khi liều 
Fentanyl ở nhóm I cao hơn hẳn so với 2 nhóm còn lại $(p<0,001)$. Đối với nồng độ fentanyl phối hợp trong giảm đau NMC, các nghiên cứu thây rằng khi sử dụng nồng độ fentanyl $1 \mu \mathrm{g} / \mathrm{ml}$ thì phải dùng tốc độ cao mới đủ giảm đau, do đó làm xuất hiện thêm tác dụng phụ của thuốc tê như mạch chậm, tụt huyết áp, ức chế vận động. Ngược lại ở nồng độ fentanyl từ $2-3 \mu \mathrm{g} / \mathrm{ml}$ thì với tốc độ truyền thấp cũng cho tác dụng giảm đau tương đương nhưng ít tác dụng phụ hơn [1].

Bảng 3 cho kết quả số phân đốt trung bình bị ức chế do gây tê ngoài màng cứng bằng ropivacain kết hợp fentanyl là 6,4 phân đốt và không có sự khác biệt có ý nghĩa giữa 3 nhóm nghiên cứu $(p>0,05)$. Kết quả này tương tự với nghiên cứu của Trân Đức Tho năm 2017 là 6,7 phân đốt ức chế trung bình. Nghiên cứu không tìm thấy sự khác biệt có ý nghĩa giữa các nhóm nghiên cứu về thời gian khởi phát tác dụng giảm đau $(p>0,05)$. Trung bình thuốc tê khởi phát tác dụng giảm đau sau 8,8 $\pm 1,9$ phút. Kết quả này tương đương với nghiên cứu của Trần Đức Thọ (2017) với trung bình 8,8 phút ở nhóm LC và LF [1].

Bảng 4 cho thấy tổng số lần bấm trung bình của bệnh nhân ở nhóm II và III tương đương nhau (15,9 lần và 15,7 lần) và thấp hơn hẳn so với nhóm I (18,2 lần), sự khác biệt có ý nghĩa thống kê với $p<0,001$. Trong khi đó, tỷ lệ bấm thành công giảm dần lần lượt từ nhóm I $(88,4 \%)$ đến nhóm III $(78,2 \%)$. Kết quả này tương tự một số nghiên cứu trong nước trước đây với tỷ lệ A/D dao động trong khoảng $70-90 \%$ [1]. Tổng số lần bấm thấp và tỷ lệ thành công cao trong nhóm II có thể là dấu hiệ̂u cho thấy người bệnh giảm đau nhanh hơn mổi khi có nhu cầu giảm đau. Đây là một kết quả cho thây hiệu quả của ropivacain với nồng độ $0,125 \%$, cũng như tác dụng của PCEA trong giảm đau sau mố.

Kết quả nghiên cứu cho thây hiệu quả giảm đau của hỗn hợp thuốc trong nghiên cứu chỉ mất khoảng 15 phút để đạt được điểm VAS mục tiêu (dưới 3) ở các thời điểm bệnh nhân nghỉ $\left(\mathrm{H}_{0.25}-\right.$ $2,2 \pm 0,6)$, trong khi thời gian đạt điểm VAS mục tiêu ở thời điểm bênh nhân ho là khoảng 8 tiêng $\left(\mathrm{H}_{8}-2,93 \pm 0,04\right)$. Việc duy trì được điểm VAS tốt cũng phản ánh được thực trang nghiên cứu có sự hợp lý trong các hỗn hợp thuốc sử dụng và cài đặt thông số của PCEA.

Biểu đồ 1 và 2 thể hiện sự thay đổi của điểm VAS khi nghỉ và khi ho/vận động ở các thời điểm khác nhau. Như vậy điểm VAS khi nghỉ và khi ho của các bệnh nhẩn ở nhóm II và III thấp hơn nhóm I có ý nghĩa thống kê với $p<0,05$ ở hầu hết các thời điểm theo dõi. Ngược lại, không có sự khác biệt đáng kể giữa nhóm II và nhóm III $(p>0,05)$. Kết quả này tương tự với nghiên cứu của Shantiraj G. (2018), trong đó hỗn hợp giảm đau với ropivacain bắt đầu đạt hiệu quả mong đợi tại thời điểm 1 giờ hậu phẫu [8]. Kết quả này tương tự với nghiên cứu của Trần Đức Thọ cũng có giảm đau khi ho hiệu quả ở thời điểm 16 giờ [1].

Mức độ hài lòng của bệnh nhân cũng được coi là một yếu tố quan trọng để đánh giá hiệu quả của phương pháp vô cảm. Bảng 6 cho thấy mức độ hài lòng đến rất hài lòng của bệnh nhân nhóm II đat $100 \%$, trong khi nhóm I và nhóm III chỉ đạt lần lượt là $81,9 \%$ và $77,1 \%$. Sự khác biệt này có ý nghĩa thống kê với $p<0,001$. Nghiên cứu của Trần Đức Thọ (2017) [1] cũng chỉ ra kết quả tương tự với tỷ lệ hài lòng ở bệnh nhân của 2 nhóm nghiên cứu lần lượt là $88 \%$ và $85 \%$. Nghiên cứu của Fowler (2008) cho thây các bệnh nhân được áp dụng kỹ thuật giảm đau NMC có mức độ hài lòng vượt trội so với phương pháp giảm đau thông thường [2]. Nghiên cứu của Eid EA (2007) cũng chỉ ra mức độ hài lòng lên tới $100 \%$ ở hai nhóm bệnh nhân giảm đau ngoài màng cứng với bupivacaine $0,125 \%$ và $0,25 \%$ với điểm hài lòng trung bình lần lượt là $9,2 / 10$ và $9,3 / 10$ [6].

\section{KẾT LUẬN}

Qua nghiên cứu về hiệu quả giảm đau NMC ngực với hỗn hợp ropivacain nồng độ $1 \%$, $0,125 \%, 0,2 \%$ và fentanyl $2 \mathrm{mcg} / \mathrm{ml}$ do người bệnh tự điều khiển ở bệnh nhân được phẫu thuật mở ổ bụng, chúng tồi rút ra kết luận: hỗn hợp ropivacain $0,125 \%$ + fentanyl có hiệu quả giảm đau tốt nhất với tổng liều ropivacain tương đương với ropivain $0,1 \%$ (276mg so với $232 \mathrm{mg}$ ) và ít hơn ropivacain $0,2 \%(446,1 \mathrm{mg})$; trong $\mathrm{khi}$ đó số lần bấm PCA tương đương với ropivacain $0,2 \%$ (lần lượt 15,9; 15,7), và ít hơn ropivacain $0,1 \%(18,2)$; điểm VAS lúc nghỉ và khi ho/vận động của nhóm sử dụng nồng độ ropivacain $0,125 \%$ và $0,2 \%$ thấp hơn đáng kể so với nhóm sử dụng nồng độ $0,1 \%$.

\section{TÀI LIẸU THAM KHẢO}

1. Trân Đức Thọ (2017), Nghiên cứu tác dụng giảm đau sau mổ bụng trên của Levobupivacain phối hợp với Sufentanil hoặc Fentanyl hoặc Clonidin qua catheter ngoài màng cứng bệnh nhân tự điêuu khiên, Luận án Tiến sĩ $Y$ học, Viện nghiển cứu Khoa học Y̛ Dược Lâm sàng 108.

2. Fowler S. J., et al (2008), "Epidural analgesia compared with peripheral nerve blockade after major knee surgery: a systematic review and meta-analysis of randomized trials", $\mathrm{Br}$ ] Anaesth. $100(2)$, p. 154-64. 
3. Grass J. A. (2005), "Patient-controlled analgesia", Anesth Analg. 101(5 Suppl), p. S44-61.

4. Kulkarni Anita, et al (2018), "A comparative study of ropivacaine and bupivacaine with fentanyl for postoperative patient-controlled epidural analgesia after major abdominal oncosurgery". 1(2), p. 66-72.

5. Liu S. S., Allen H. W., Olsson G. L. (1998), "Patient-controlled epidural analgesia with bupivacaine and fentanyl on hospital wards: prospective experience with 1,030 surgical patients", Anesthesiology. 88(3), p. 688-95.

6. Eid Essam A., Alsaif Faisal A. (2007), Combined Epidural-General Anesthesia (CEGA) In Patients
Undergoing Pancreatic Surgery: Comparison Between Bupivacaine 0.125\% And 0.25\%.

7. Lv Bao-sheng, et al (2014), "Efficacy and safety of local anesthetics bupivacaine, ropivacaine and levobupivacaine in combination with sufentanil in epidural anesthesia for labor and delivery: a metaanalysis", Current Medical Research and Opinion. 30(11), p. 2279-2289.

8. Shantiraj Gunna, Kalyan Sankula (2018), "A study on evaluation of epidural levobupivacaine $0.125 \%$ and ropivacaine $0.125 \%$ with and without fentanyl for postoperative pain relief in abdominal surgeries", Journal of Evidence Based Medicine and Healthcare. 5, p. 2174-2179.

\section{CÁC YẾU TỐ NGUY Cơ CỦA HUYẾT KHỐI TĨNH MACH SAU PHẪU THUÂ̂T TIỆT NIỆU: MộT NGHIÊN CỬU BÊ̂NH CHỨNG TỪ DỮ LIỆU BẢO HIỂM QUỐC GIA}

\section{TÓM TẮT}

Nghiên cứu mô tả cắt ngang được tiến hành trên 145.479 người bệnh phẫu thuật tiết niệu từ 1/2017 đến 9/2018. Người bệnh được đánh giá điểm số nguy cơ trước phẫu thuât theo thang điểm Caprini hiêu chỉnh và được theo dõi trong khoảng thời gian 30 ngày sau phẫu thuật để xác định tỷ lệ huyết khối tĩnh mạch (HKTM). Phân tích hồi quy đa biến được thực hiển nhằm xác định các yếu tố nguy cơ liên quan đến HKTM sau phẫu thuật. Có 92 người được chẩn đoán mắc HKTM sau phẫu thuật trong vòng 30 ngày (chiếm tỉ lệ 0,06\%). Số người có điểm Caprini 3-4 điểm chiếm tỷ iệ nhiều nhất $(49,3 \%)$. Điểm Caprini càng cao thì nguy cơ mắc HKTM sau phẫu thuật tiết niệu càng tăng. Các yếu tố nguy cơ liên quạn có ý nghĩa $(p<0,001-0,01)$ đối với HKTM sau phẫu thuật tiết niệu bao gồm tuổi $>60$, tiền sử nhồi máu cơ tim, loét dạ dày, tiểu đường, ung thư, tăng huyết áp, suy tĩnh mạch, suy thận, tiền sử huyết khối, bệnh mạch máu ngoại vi. Các yếu tố này cần được đánh giá trước phấu thuật nhằm hỗ trợ ra quyết định dự phòng huyết khối tĩnh mach thích hợp trên lâm sàng.

Tư khóa: Huyết khối tĩnh mạch, yễu tố nguy cơ, phẫu thuật tiêt niệu

\section{SUMMARY \\ RISK FACTORS OF VENOUS THROMBOEMBOLISM AFTER UROLOGICAL}

\footnotetext{
${ }^{1}$ Trường Đại Học Y Hà Nội

${ }^{2}$ Bênh viện đại họ Y Hà Nôi

Chịu trách nhiệm chính: Bùi Mỹ Hạnh

Email: buimyhanh@hmu.edu.vn

Ngày nhận bài: 9.3.2021

Ngày phản biên khoa học: 27.4.2021

Ngày duyệt bài: 10.5.2021
}

Bùi Mỹ Hạnh ${ }^{1,2}$, Hoàng Long1,2

\section{SURGERY: A DISEASE STUDY FROM} NATIONAL INSURANCE DATA

A descriptive cross-sectional study was conducted on 145,479 urology patients from January 2017 to September 2018. The patient was assessed for the risk score before surgery according to the adjusted Caprini risk assessement model and was monitored for a period of 30 days after surgery to determine the rate of venous thromboembolism (HKTM). Multivariate regression analysis was performed to identify the risk factors associated with the postoperative venous thromboembolism. There were 92 people diagnosed as having venous thrombosis after surgery within 30 days (accounting for $0.06 \%$ ). The number of people with a Caprini score of 3-4 accounts for the highest proportion (49.3\%). The study showed that the higher the Capriniscore, the greater the risk of developing venous thromboembolism after urological surgery. The relevant risk factors $(p<0.001)$ for post-urinary surgery include age $>60$, history of myocardial infarction, gastric ulcer, diabetes, cancer, hypertension, varicose vein, renal failure, history of thrombosis, peripheral vascular disease. These factors need to be assessed prior to surgery in order to assist in making clinically appropriate decisions for venous thromboembolism prevention.

Key words: VTE, risk factors, urology patients.

\section{I. ĐẶT VẤN ĐỀ}

Huyết khối tĩnh mach là tình trang huyết khối làm tắc một phân hay toàn bộ tĩnh mạch sâu. Phân lớn HKTM không có triệu chứng lâm sàng, theo nghiên cứu của Pannucci $\mathrm{CJ}$ chỉ có $11 \%$ NB có triệu chứng lâm sàng [1]. Do vậy việc tâm soát và phòng ngừa bệnh này là cân thiết để phát hiện sớm, điều trị và ngăn chặn các biến chứng. Trong các thang điểm đang được sử dụng để phân tâng yếu tố nguy cơ HKTM, thang 